\title{
Structures, Algorithms and Stone/Timber Prototypes
}

\author{
Micaela Colella ${ }^{1}$
}

Published online: 25 July 2016

(C) Kim Williams Books, Turin 2016

\begin{abstract}
A one-day seminar on structures, algorithms and stone/timber prototypes was held on 11 January, 2016 at the Department of Civil Engineering and Architecture (DICAR) of the Politecnico di Bari. The event included an exhibition of student work, in the morning session, followed by a series of lectures by international academics.
\end{abstract}

Keywords Digital stereotomy · Post-formed grid shell · Thin shell · Computational morphogenesis · Algorithms in architectural design · Genetic algorithm

'Structures, algorithms and stone/timber prototypes' was a one-day seminar held at the Politecnico di Bari on 11 January, 2016. The event was organized by the New Fundamentals Research Group (https://www.youtube.com/channel/UClaLNkbf2ms Xg8GqyA7yHiA), a team of Italian architects and academics coordinated by Prof. Giuseppe Fallacara. The team is affiliated to the Department of Civil Engineering and Architecture (DICAR) of the Politecnico di Bari, and develops research projects which deal with the relationship between innovation and tradition in architecture. Since its founding, New Fundamentals has carried out research work on digital stereotomy, the history of construction, and sustainable housing in the Mediterranean area. Its activities include teaching/learning activities, publishing textbooks, organizing lectures, workshops, and supervising Master's and Ph.D. theses.

Micaela Colella

micaela.colella@uniroma3.it

1 Dipartimento di Scienze dell'Ingegneria Civile e dell'Architettura, Politecnico di Bari,

Consorzio Argonauti: Università degli Studi Roma Tre-Politecnico di Bari, Via Orabona 4, 70125 Bari, Italy 
New Fundamentals strongly believes in the need to develop a network with relevant research institutes and universities. Thus, this one-day seminar was conceived in the spirit of sharing, with Italian and international colleagues, the conclusions of ongoing research projects on digital design and the fabrication of complex forms, in order to highlight and discuss the potential for future collaborations.

The morning session was dedicated to the exhibition of works developed by students of the Politecnico di Bari, and the presentation of research prototypes built by New Fundamentals. The students' works, which included posters and physical models, were the outcomes of a third-year design studio, led by Prof. Giuseppe Fallacara and taught with the support of Maurizio Barberio and Micaela Colella, both Ph.D. candidates at the Politecnico di Bari. The posters and models exhibited illustrate an experimental teaching/learning approach which Prof. Fallacara tested during the design studio. This approach was inspired by the concepts of 'Experiential Learning' and 'Flipped Classroom', consisting in a series of 'cooperative classes', where tutors and students interacted and discussed ideas in an absolute spirit of intellectual equality.

The goal was to simulate the activity of a large architecture practice involved in the design of a public building, which generally requires the contribution of a large number of architects and designers. The students were given a brief for a new museum and multipurpose centre in Matera, Italy, which was recently nominated European Capital of Culture 2019. They had to deliver a design proposal, a rapid prototyped model and a short video. In response, the students submitted a project characterized by a large elliptical funnel-shaped perforated roof, composed of hexagonal elements made of six prismatic ashlars, pre-compressed through a metal band (Fig. 1). The spatiality generated by the roof is meant to evoke the strong Mediterranean tradition of generating vaulted spaces. The perforated roof allows natural light to enter, while the glazed perimeter triggers a dialogue between the

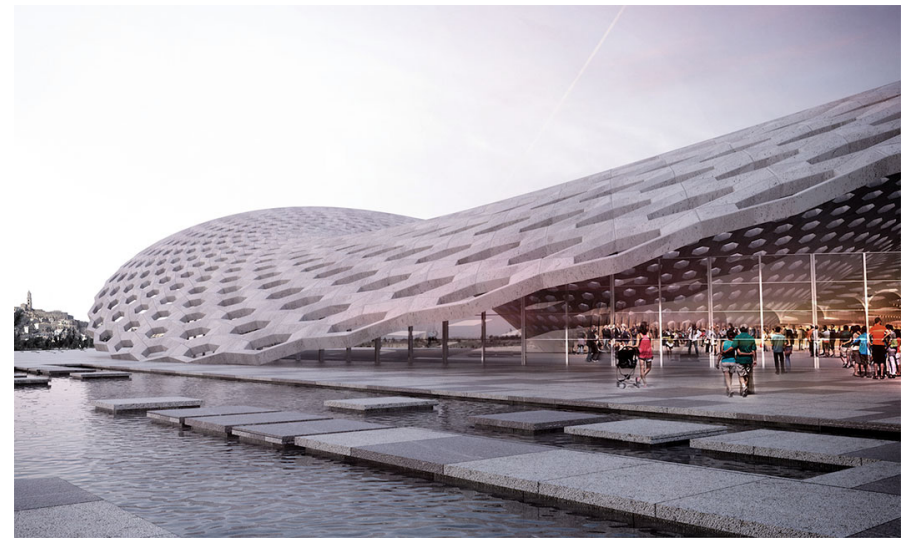

Fig. 1 Image from a student poster showing the elliptical funnel-shaped perforated roof 
museum interior and the surrounding landscape, while also gives the building a higher permeability that overcomes the functional limits of a conventional museum.

The research prototypes are the partial results of several research projects of the New Fundamentals Research Group, developed together with undergraduate and Ph.D. candidates, in partnership with companies active in the stone industry. One of the showcased prototypes was related to the research project Stone Skin, developed with the Swiss company Generelli SA. Stone Skin investigates the use of single or double curvature shells, constituted by ultralight granite or marble panels reinforced with layers of carbon or glass fibre. The panels, both intrados and extrados, will be juxtaposed and fixed to each other through simple bolted connections in proximity of the four vertices of each panel. Another interesting aspect is the possibility to use backlit panels, through the application of LEDs or photo luminescent films, in combination with the use of glass fibre in the rear part.

Another prototype showcased was 'Wave block wall', an application of the patent by Yuri Estrin and his research group (A. Dyskin, E. Pasternak, Khor Han Chuan, G. Simon, A. Molotnikov and L. Goldin). This prototype, made of limestone by Pimar and of cast stone by Tarricone Prefabbricati, is based on the principle of topological interlocking and analyses the properties of the mortarless structures whose design is based on this principle. It concerns of structures built of 'osteomorphic blocks': blocks possessing specially engineered contact surfaces that allow the assemblage of various 2D and 3D structures. These structures are easy to build and can be demountable; they are flexible, resistant to macroscopic fractures and tolerant to missing blocks. The blocks are kept in place without keys or connectors, which are the weakest elements of the conventional interlocking structures. The overall structural integrity of these structures depends on the force imposed by peripheral constraint (Fallacara and Minenna 2014).

The afternoon session was opened by Prof. Claudio D'Amato Guerrieri, former Director of the DICAR. Dr. Alberto Pugnale, Architect and Lecturer in Architectural Design at the Melbourne School of Design was the first speaker. In his presentation, Pugnale started outlining a brief history of form-finding methods and illustrative architectures. He described, for instance, the works by Antoni Gaudí, Felix Candela, Frei Otto, Heinz Isler and Dante Bini, showing how designers were challenged, at that time, in the articulation of spaces from the intrinsic characteristics/rules of structural forms. Thus, Pugnale traced the intricate path which led architects towards the contemporary trend of free-form structures, experimentations with mathematical optimization and parametric design techniques. He defined the concept of 'Computational Morphogenesis' as the way through which designers are recently using optimization to support conceptual design. He illustrated it by showing the research work he carried out in 2007 on the Kakamigahara Crematorium. In that case study, the roof shell was described by means of a NURBS surface in Rhinoceros ${ }^{\circledR}$, its control points constrained in correspondence to the pillars, and the spatial coordinates of the remaining ones automatically becoming the design variables of the system. A Genetic Algorithm optimization procedure was then added, guiding the study and evaluation process of the architectural form (Pugnale and Sassone 2007: 161-166). The concept of 'Computational Morphogenesis' was then taken to an extreme, by presenting a 

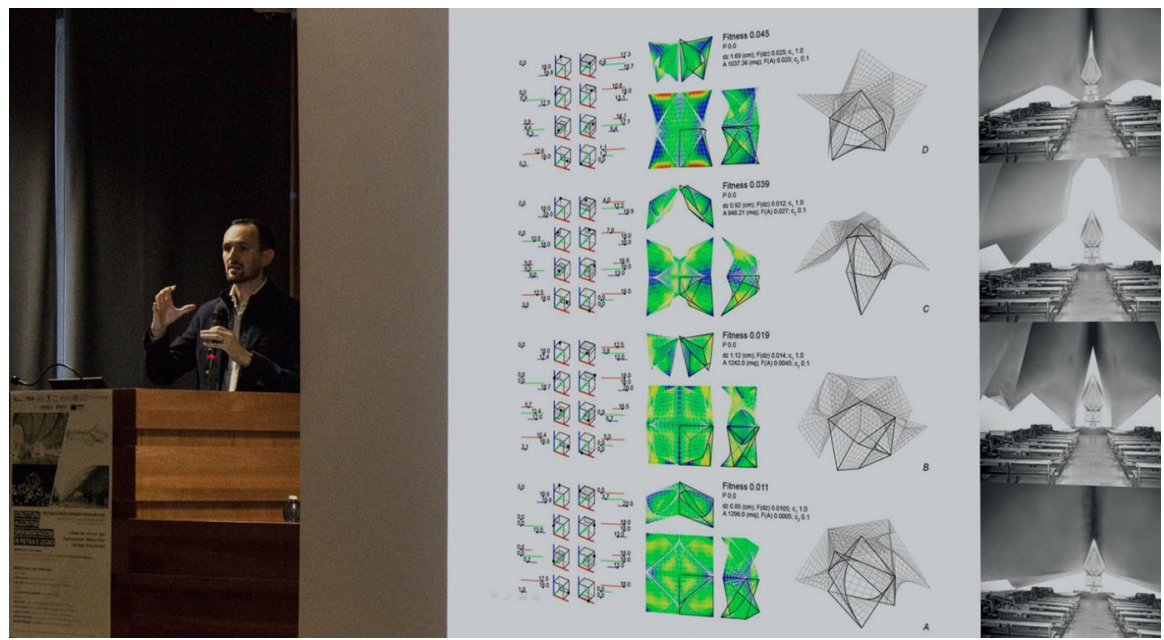

Fig. 2 Alberto Pugnale and the computational morphogenesis of the church of Longuelo. Photo: Bianca Parenti

possible parametric redesign of the Church of Longuelo, in Italy, which was performed by Pugnale in collaboration with Alessandro Liuti, Ph.D. candidate at the Melbourne School of Design (Liuti and Pugnale 2014). The original design was parameterized from the concepts which generated the project, and not from the formal outcome (Fig. 2).

The second speaker was Dr. Sofia Colabella, Architect and Sessional Lecturer in Technology of Architecture at the University of Naples 'Federico II' and at the MSD, but also co-founder, together with Sergio Pone, Bianca Parenti and Daniele Lancia, of the research group 'Gridshell.it' (http://www.gridshell.it/). Her lecture focused on timber post-formed grid shells, which is one of the research topics she has been working on since her Ph.D. By means of an historical analysis of grid shell antecedents, she highlighted the technical issues that could arise when designing free-form grid shell structures. Such aspects that were illustrated through a continuous comparison of digitally generated forms, which could represent abstract optimal shapes with actual grid shells and show the limits of real construction (Fig. 3). The presentation carried on with a report on Gridshell.it projects and its research experiences, giving equal weight on the development of digital design tools in Grasshopper ${ }^{\circledR}$, a plug-in for Rhinoceros ${ }^{\circledR}$, and the realisation of timber grid shells (Pone et al. 2013).

Sergio Pone, Associate Professor in 'Technology of Architecture' at the Università degli Studi di Napoli Federico II, was the third speaker and brought on stage a research work on a wooden acoustic shell for open-air chamber music concerts, which is branded as 'ReS'. The structure was developed during International Summer School 'Villa Pennisi in Musica' (http://www.vpmusica. $\mathrm{com} /$ ), where music and architecture are combined in a unique teaching/learning approach (Fig. 4). 

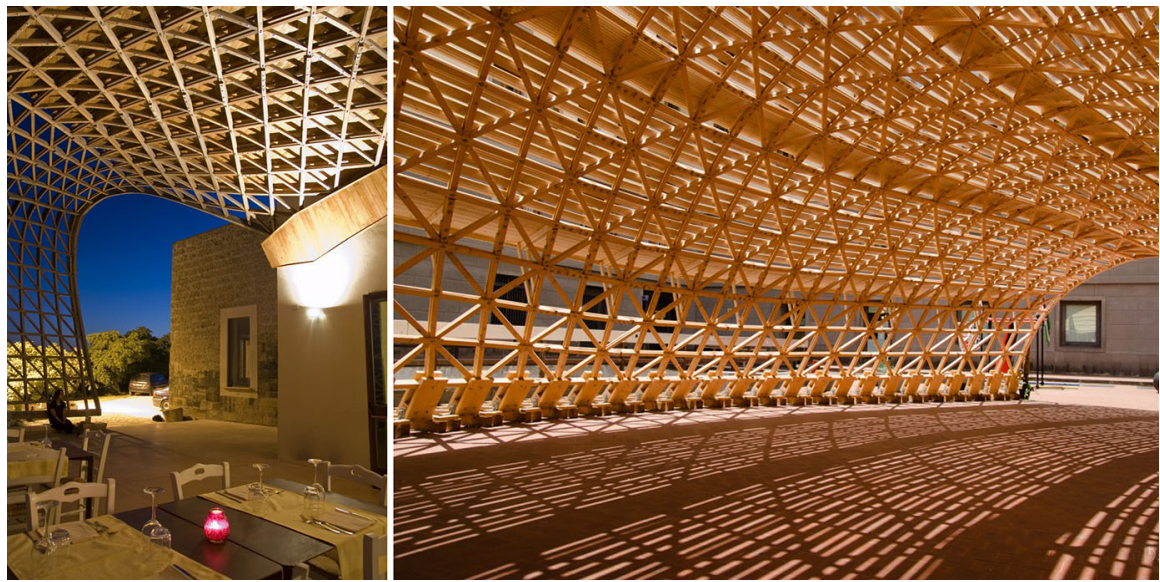

Fig. 3 Trio Gridshell (Lecce) and Toledo Gridshell (Naples) designed and built by Gridshell.it. Photo: Daniele Lancia
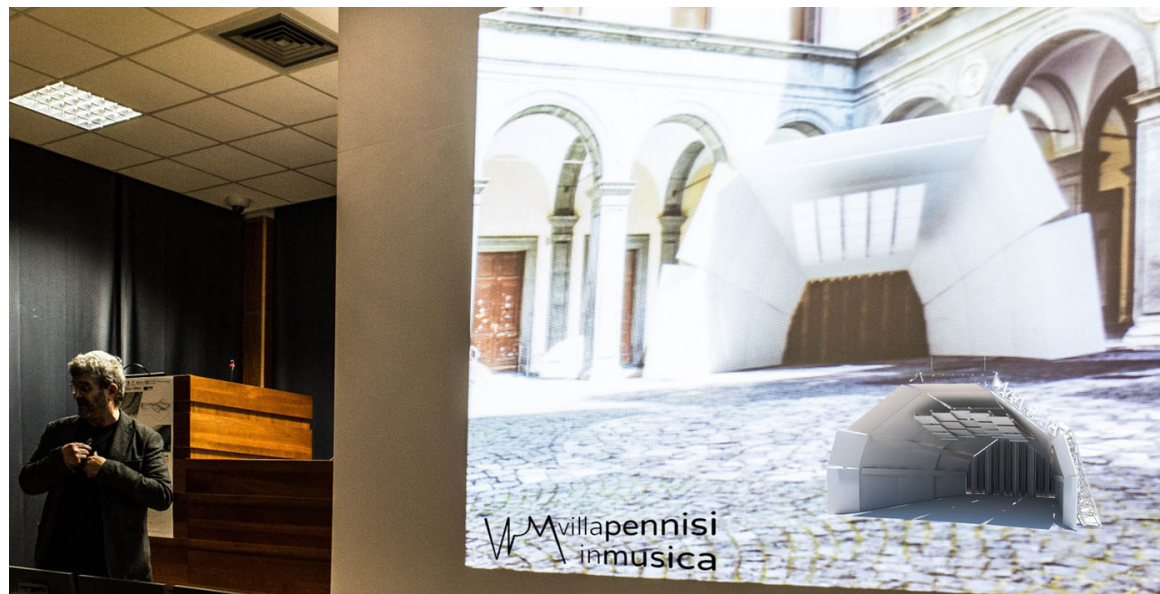

Fig. 4 Sergio Pone during the lecture, talking about Villa Pennisi in Musica Summer School. Photo: Bianca Parenti

In the ReS project, a sophisticated digital form finding process lies behind the design of a simple acoustic shell, where each and every part of the structure is made of timber and reversible joints, therefore permitting easy manufacturing, a sustainable process and cost effective construction. The digital simulation is performed through parametric modelling and a multi-objective Gridshell.it Genetic Algorithm optimization process. The $\operatorname{ReS}$ project, a collaboration between the acoustic department of Buro Happold Engineers and the Department of Architecture of the Università degli Studi di Napoli Federico II', has been under development since 2012 (Pignatelli et al. 2015). 


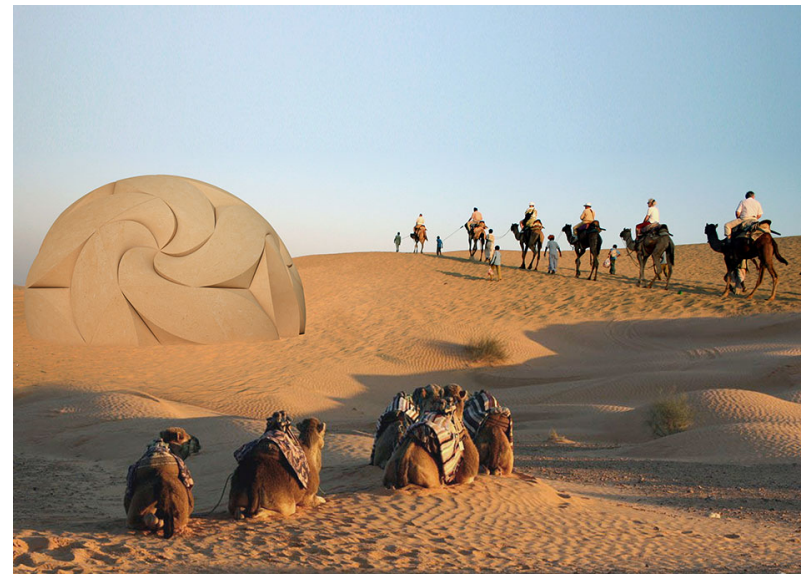

Fig. 5 An image of the Ghibli dome. Photo: Micaela Colella

At the hosts' presentation, Giuseppe Fallacara intervened, with a comprehensive lecture on stereotomy, from his own hypothesis on the origin of the term, up to current trends in this historical discipline, using new tools such as 3D parametric tools or CNC machines for the stone manufacturing. These are topics in which he has been involved for at least a decade, with continuous realization of stone prototypes of increasingly daring and futuristic experimental structures, of which he showed some examples (Fallacara 2007).

In the closing session, the intervention of Maurizio Barberio, Ph.D. candidate from the Politecnico di Bari, who presented the partial results of his doctoral research on the use of the most advanced parametric tools for the exploration of complex shapes applied to the stone architecture and design. His presentation focused on the description of modelling and manufacturing processes of some of the ongoing prototypes designed by him and his group. One of these is an experimental geodesic dome named 'Ghibli', designed by Giuseppe Fallacara and Micaela Colella, a minimal housing unit for life in deserted areas, characterized by rapid construction, thanks to the assembly of few molded plastic blocks, filled with sand after assembly (Fig. 5). The home is energetically and hydraulically self-sufficient thanks to five small wind turbines and a condensed water collection system.

All lectures, activities and projects of the New Fundamentals Research Group are available on the group's YouTube channel (https://www.youtube.com/channel/ UClaLNkbf2msXg8GqyA7yHiA/videos).

\section{References}

Fallacara, Giuseppe. 2007. Verso una progettazione stereotomica. Nozioni di Stereotomia, Stereotomia digitale e trasformazioni topologiche: ragionamenti intorno alla costruzione della forma. Rome: 
Aracne Editrice ISBN 8854812285. http://www.atelierfallacara.it/_download/Monografie/3_Verso_ una_progettazione_stereotomica.pdf

Fallacara, Giuseppe and Vincenzo Minenna. 2014. Stereotomic Design. Maglie (Lecce): Tipografie Gioffreda. ISBN 978-88-940228-0-3. http://www.architetturadipietra.it/wp/wp-content/uploads/ 2014/09/G.-Fallacara-V.-Minenna-STEREOTOMIC-DESIGN.pdf

Liuti, Alessandro and Alberto Pugnale. 2014. Computational morphogenesis applied to the church of Longuelo. In: 48th International Conference of the Architectural Science Association, 2014: 405-416. http://anzasca.net/wp-content/uploads/2014/12/08_32_190.pdf

Pignatelli, Eduardo, Sofia Colabella, Serafino Di Rosario, Sergio Pone. 2015. A wooden acoustic shell for open-air chamber music concert. In: Future Visions: Proceedings of the International Association for Shell and Spatial Structures Symposium 2015. Amsterdam. https://www.researchgate.net/ publication/281748470_A_wooden_acoustic_shell_for_open-air_chamber_music_concert

Pone, Sergio, Sofia Colabella, Andrea Fiore, Daniele Lancia, Bernardino D’Amico, Bianca Parenti. 2013. Timber post-formed Gridshell: Digital Form Finding/Drawing and Building Tool. In: Beyond the limits of man, eds. J. B. Obrebski and R. Tarczewski. Wroclaw: IASS. https://www.researchgate. net/publication/261285620_Timber_post_formed_grid_shell_digital_form_finding_drawing_and_ building_tool

Pugnale, Alberto and Mario Sassone. 2007. Morphogenesis and Structural Optimization of Shell Structures with the Aid of a Genetic Algorithm. Journal of the International Association for Shell and Spatial Structures 48(3):161-166. http://www.findanexpert.unimelb.edu.au/display/ publication 181202

Micaela Colella is an architect and Ph.D. candidate at the Università degli Studi Roma Tre and Politecnico di Bari. Her research focus is on advances in prefabrication systems which use natural materials for sustainable houses in the Mediterranean area. She is partner and founder of "New Fundamentals Research Group". 